\title{
Using the student voice to enhance the teaching of undergraduate courses with high failure rates
}

\author{
Erik Blair, The University of the West Indies, St. Augustine, Trinidad and Tobago, West Indies
}

\begin{abstract}
Whilst it is likely that some students will fail a course, it is important for universities to determine whether such failure is a personal outcome or whether there are aspects of the course that could be more conducive to student learning. In adopting a student-centred approach, this research analysed data drawn from student evaluation questionnaires (SEQs) in order to establish how students thought the teaching of undergraduate courses with high failure rates could be improved. Many higher education institutions use SEQs as tools for gathering data on the teaching and learning experience, but the emphasis here is on how such data can be used. Content analysis was used to map the SEQs of students enrolled on 19 courses with high failure rates against a baseline developed from the SEQs of students enrolled on 19 courses with low failure rates. This paper examines these responses and makes five recommendations specifically aimed at improving undergraduate courses with high failure rates.
\end{abstract}

Keywords: Student evaluation questionnaires; student voice; failure rates

\section{Introduction}

At a time when universities are under increased scrutiny and are, in many countries, routinely examined to assess their worth, it seems rather counter-intuitive that there has been little research on university course failure (Haynes Stewart et al., 2011; Wimshurst \& Allard, 2008) and that most of the literature that has looked at undergraduate attainment has focused on academic success (Peelo, 2002). Perhaps the nature of research in this field (where one colleague is analysing the outcomes of another) has led to a focus on the positive. Or perhaps those researching this area show a preference for the positive as a means of finding methods that work and that could be applied elsewhere in order to reproduce such success. In either case, it seems inappropriate to ignore failure in the university system and here it is proposed that one way of examining courses with high failure rates is through listening to the student voice.

Seale (2009) suggests that universities should feel committed to hearing the voice of their students and Cook-Sather (2006) proposes that student feedback tools offer valid mechanisms for capturing this voice. Many institutions use student evaluation processes as a way of highlighting course and lecturer strengths and areas for improvement. As well as evaluating lecturers, student evaluation questionnaires (SEQs) give us an insight into institutional ideologies and methodologies (Magnusson, 1998) and as such the process is able to highlight both what is important to the individual student and what is important to the institution. Student evaluations offer first hand data that can be used to enhance practice. 
Greenwald (2002) argues that SEQs are important tools for gathering the student perspective on teaching effectiveness - a position that is developed through Marsh and Bailey's (1993) proposal that such perspectives are multi-dimensional rather than superficial in their coverage. There is no significant difference in how students evaluate different courses or disciplines, nor does gender (the student's or the lecturer's) significantly impact upon evaluations (Freeman, 1994) such that 'students' evaluations primarily reflect the effectiveness of the instructor rather than the influence of the course' (Marsh, 1984, p.719). The legitimacy of using SEQs as a means of hearing the student voice is reinforced by Hellman (1998) who reports that they offer statistical and methodological validity; which suggests that data developed from them is robust and fit for purpose. Piccinin et al. (1999) offer further support for the use of SEQs in discussing their reliability, and ability to garner valuable insight.

Whilst there may be debate in some areas regarding the use of SEQs, in a meta-analysis and review of the literature, Clayson (2009) found that whilst students do not always 'hold a realistic evaluation of their own learning' (p.27), there is a clear relationship between learning and student evaluations, and that SEQs are valid instruments for measuring this. SEQs offer a secure and anonymous method for students to give feedback on courses and lecturers (Weinberg et al., 2009; Marsh, 1987) and 'evaluation systems place a high premium on confidentiality and nondisclosure' (Clayson \& Haley, 2011, p.105). In their study of 1246 students using paperbased SEQs, Layne et al. (1999) reported that $87 \%$ of the students perceived that SEQs allowed them to give anonymous feedback. Thus, not only is the use of SEQs secure in relation to quality assurance but SEQs are also generally perceived to be anonymous - thus increasing the likelihood of students answering them truthfully.

Emery et al. (2003) suggest that teaching effectiveness can only be assessed on outcomes and their key criticism of student evaluation systems is not about the way that the data is gathered, but about the way that the data is used: moving the focus from the completion of SEQs to the implementation of the resultant data. In this regard, for an SEQ to be an effective tool, students need to perceive it to have impact. If students don't feel that their feedback is having an impact on the course or enhancing its teaching then they may be less likely to complete future SEQs (Spencer \& Schmelkin, 2002). In all we can see that SEQs empower students through giving them a voice with which to assess their own experience of learning (Tucker et al., 2008) but that there needs to be clear consideration given regarding what is done with the resultant data.

Academic failure is not just a matter of academic weakness and has been linked to a number of different social, cultural, cognitive and affective constructs including: levels of effort (Bornholt \& Möller, 2003); levels of goal-orientation (Turner et al., 2002), and group norms and expectations (Mortenson, 2006). More likely, failure is the blending of these (and other) constructs to develop multi-dimensional interrelationships that incline towards failure (Forsyth $e t$ al., 2009; Ling et al., 2003; Wimshurst \& Allard, 2008). Moreover, studies have found a rather vicious circle regarding how students consider failure, in that students who become preoccupied with possible failure have higher failure rates (Struthers et al., 1996; Weiner, 1995). In all, we find that academic failure is a complicated issue and the 'problem' of failure is ripe for further scrutiny. Exploration of all the causes of failure is outside the remit of this research but through problematizing links between courses with high failure rates and students' perceptions of the teaching they received, it is hoped that some light will be shone into this dark corner. 
This paper discusses the use of SEQs as a means to offer student-centred feedback on courses with high failure rates and resultant guidance on how students feel such courses can be improved. As such, it takes SEQs to be valid and reliable tools (Greenwald, 2002; Marsh \& Bailey, 1993; Hellman, 1998; Piccinin et al., 1999) whilst addressing Clayson's (2009) concerns about differences across various faculty by using data from a broad spread of courses. This research adopted a phenomenological perspective, assuming that one piece of data is enriched through its interplay with other pieces of data. Data from 1665 SEQs drawn from 38 undergraduate courses taught at a Caribbean university during semester 1 of the academic year 2011/12 was analysed to establish how students reported courses could be improved. This was done through content analysis of qualitative responses on the SEQs of 19 courses with high failure rates $(\geq 50 \%)$ mapped against baseline data established through the analysis of 19 courses with low failure rates $(\leq 25 \%)$.

This research aimed to establish how students on courses with high failure rates felt the teaching on these courses could be enhanced by examining their responses to one question on their SEQ: 'How do you think this course could be improved?'

\section{Student evaluations of teaching effectiveness}

Kotze and Du Plessis (2003) found that student satisfaction is a fair measure of teaching effectiveness and Richardson et al. (2007) found that such satisfaction is increased in line with the support that lecturers offer and students' perceptions of apparent teaching skills. Whilst some may question the subjective nature of such feedback, if we hope to assess the learning situation it only seems right to hear the learners' voice. It is also worth noting that 'when students learn more ... their opinion of the course/teacher will be higher' (Patrick, 2011, p.248) such that student satisfaction is the result of good teaching and not the grades that a student achieves on a course. Not surprisingly, Richardson et al. (2007) found that teaching skills and teacher support showed the highest correlation with overall satisfaction, whilst research by Chamorro-Premuzic and Furnham (2005) points to what we already intuitively know - that students want lecturers who support their particular needs.

Teaching influences learning and the type of teaching influences that type of learning that occurs (Kember, 1997; 2000). There are many potential teaching methods available to a course lecturer and student evaluations can be used to help gauge their effectiveness. The size of the class will affect pedagogical decisions and will affect the learning environment. Likewise, certain courses can only be taught in specific situations (ICT suites, laboratories, workshops etc.); however Beran (2005) found no significant difference in the way that students evaluate different disciplines. While there is a negative impact of class size on student evaluations of lecturers' effectiveness (Bedard \& Kuhn, 2008) this is only true up to point, after which students may feel that there are some advantages to being relatively anonymous, and class size does not affect student evaluations of lecturers in upper-level courses (McPherson et al., 2009). Through this we can see that certain variables are always at play but globally the specifics of course content, resources and class size are not as important to student evaluations as good teaching (Kotze \& Du Plessis, 2003; Marsh, 1984; Freeman, 1994). 
Lecturing is still a key component of undergraduate university education and about $80 \%$ of student-lecturer contact time occurs in the lecture theatre (Thielens, 1987). Good and Brophy (2003) highlight a number of occasions where lecturing might be the best teaching technique, but warn that the effectiveness of the lecture is dependent on the quality of the delivery and the quality of the preparation. McKeachie et al. (1986) found that, when it came to remembering low-level information over short periods of time, the lecture was just as effective a tool as any other teaching method, but that the content of these lectures was not retained by the students for very long. This suggests that a second stage of teaching (perhaps a tutorial) would be a useful method for helping concretise the lecture information. Tutorials should not be a mere extension of the lecture (especially if students do not feel that the lecture is effective). Instead, tutorials should offer the chance for learning to take a new direction that embraces the teacher-student dynamic.

In examining the teaching practices that give rise to better academic outcomes, Ling et al. (2011) recommend that lecturers focus on helping students achieve higher-order learning outcomes. Such an approach is not the result of the transmission of facts and figures as this will only result in surface learning, instead lecturers should see themselves as facilitators of learning - guiding, probing and supporting student enquiry-based learning. Increasingly we see the place for interactive teaching and learning in the university. Interaction in the university lecture theatre need not involve a large scale remodelling of the environment so as to allow for dynamic role plays and group work involving the use of huge sheets of paper. Interaction can also exist at a cognitive level, where reflective questioning can be introduced during a lecture (Reneland \& Ahlbäck, 2003) to allow for intrapersonal reflection and engagement. The lecture hall can also be the catalyst for interaction when topics are introduced that will later be followed up with actual and/or online discussions and tutorials.

In grounding this paper in a perspective that holds the university to be a place that aims to teach and upskill the next generation, the 'problem' of failure needs to be addressed in relation to academic staff rather than students. If students have achieved the entry grades then they have shown evidence of ability; therefore, if they are then taught in an appropriate fashion we must question what it is that might cause them to fail a course. In this instance, one could propose that the failure of the student is symptomatic of the failure of their education rather than an outcome of their academic weakness.

This analysis accepts three factors in relation to courses with high failure rates:

1. Whilst it not appropriate for a university to have an 'acceptable' failure rate, it is likely in any examination system that some students will experience failure at some level

2. Failure may be a result of factors beyond intelligence, such as maturity and life events

3. The university is a place of learning and therefore has a duty to help all students overcome challenges that limit their success

Concurrent with these three factors this analysis sees teaching and learning as the solution to academic failure. Students are 'switched on' by learning, and there is clear evidence that good university teaching can make a difference to student learning. The way that information is presented; the attention that staff offer their students; the level and type of questioning, and the inter- and intra-personal interaction that takes place in the learning environment are all seen as 
key ingredients in successful university education (Chanock, 2007; Margaret \& Guest, 2007; Lizzio et al., 2002). The quality of teaching is not just a driver of educational attainment but Foster (2010) suggests that it is also a driver of educational parity.

\section{Methodology}

This research gives credence to the student voice by examining undergraduate student perspectives on courses with high failure rates through analysing 19 courses that were taught in a Caribbean university during semester 1 of the academic year 2011/12 through student evaluations of them. Undergraduate degree programmes at this university last for three years (six semesters) and typically students study five courses each semester. During semester 1 of the academic year 2011/12 there were 662 undergraduate courses taught at the university under study. Of these:

- $525(79.3 \%)$ had a failure rate $\leq 25 \%$

- $115(17.4 \%)$ had a failure rate between $25-50 \%$

- $22(3.3 \%)$ had a failure rate $\geq 50 \%$

Standard deviation would suggest that there will always be a spread of results when course failure is analysed at the institutional level; however, academic failure is not something that can be easily 'accepted' and it does not seem fitting just to ignore the fate of those are the miserable end of the bell curve. It was for this reason that this paper focuses on the group of courses with failure rates $\geq 50 \%$ as a prototypical extreme: in an effort to establish if there are underpinning reasons for these high rates and what students say can be done to address them.

Of the 22 undergraduate courses with failure rates in excess of $50 \%$, only 19 submitted student evaluations to the university. The university expects that all courses ask students to complete SEQs and the fact that these were not produced for three courses may indicate some wider issues. This research sought to analyse the student evaluations of courses with high failure rates in relation to student evaluation data and the missing SEQs meant that these three courses had to be excluded from this analysis. For the 19 courses where students had completed SEQs it was then possible to examine where students felt these courses could be improved.

The SEQ were given out in hard copy during the last few weeks of each course - which meant that only students who attended class could complete it. It is normal for attendance to dip towards the end of a course but, across the whole university, 52.9\% of undergraduate students completed SEQs. The SEQs were completed before students were examined, which meant that students did not know that a particular course would have a high or low failure rate. The SEQ has two sections: a quantitative evaluation of the course and lecturer using 36 likert-type questions, followed by a five open ended questions that allowed for qualitative feedback.

Whilst all the data developed from the SEQs is important, the voice of the students is most clearly heard in their qualitative responses. Further, this research was conducted within a phenomenological paradigm where there is a greater likelihood of enriched interplay of data, theoretical clarity and deeper reflection when qualitative data is used (Giorgi, 1994). Despite the potential richness of data, it is still quite rare to focus on the qualitative aspects of SEQ 
(Wongsurawat, 2011) and this research hopes to mine this data seam as a means examine an under-examined area. Therefore, this article only examines the data developed from the qualitative responses of the SEQ. In order to establish where students felt courses could be improved, one particular question from the qualitative section of the SEQ was analysed. The focus here was on the SEQ question, 'How do you think this course could be improved?' This particular question was selected as it both highlighted areas of weakness and looked for solutions. In total 1734 students were enrolled in the 19 courses with high failure rates and 779 completed the SEQ - a response rate of $44.9 \%$ which is lower than university average undergraduate response rate. Table 1 gives an overview of the 19 courses.

\begin{tabular}{|c|c|c|c|c|c|}
\hline $\begin{array}{c}\text { Course } \\
\text { no. }\end{array}$ & $\begin{array}{c}\text { Year of } \\
\text { study }\end{array}$ & $\begin{array}{c}\text { No. of } \\
\text { students } \\
\text { registered }\end{array}$ & Failure (\%) & $\begin{array}{c}\text { Actual No. } \\
\text { of fails }\end{array}$ & $\begin{array}{c}\text { No. of students } \\
\text { who completed } \\
\text { SEQ }\end{array}$ \\
\hline $\mathbf{1}$ & 2 & 128 & 50 & 64 & 70 \\
\hline $\mathbf{2}$ & 2 & 55 & 50 & 27 & 46 \\
\hline $\mathbf{3}$ & 3 & 8 & 50 & 4 & 4 \\
\hline $\mathbf{4}$ & 3 & 90 & 50 & 45 & 50 \\
\hline $\mathbf{5}$ & 2 & 103 & 50 & 52 & 14 \\
\hline $\mathbf{6}$ & 3 & 105 & 51 & 54 & 42 \\
\hline $\mathbf{7}$ & 2 & 52 & 51 & 27 & 40 \\
\hline $\mathbf{8}$ & 2 & 30 & 53 & 16 & 26 \\
\hline $\mathbf{9}$ & 2 & 28 & 54 & 15 & 35 \\
\hline $\mathbf{1 0}$ & 1 & 140 & 54 & 76 & 65 \\
\hline $\mathbf{1 1}$ & 2 & 50 & 54 & 27 & 7 \\
\hline $\mathbf{1 2}$ & 2 & 12 & 58 & 7 & 7 \\
\hline $\mathbf{1 3}$ & 2 & 90 & 58 & 52 & 52 \\
\hline $\mathbf{1 4}$ & 1 & 206 & 60 & 124 & 34 \\
\hline $\mathbf{1 5}$ & 1 & 358 & 64 & 229 & 131 \\
\hline $\mathbf{1 6}$ & 2 & 60 & 78 & 47 & 49 \\
\hline $\mathbf{1 7}$ & 3 & 101 & 78 & 79 & 65 \\
\hline $\mathbf{1 8}$ & 1 & 19 & 79 & 15 & 8 \\
\hline $\mathbf{1 9}$ & 2 & 99 & 79 & 78 & 34 \\
\hline & & & & & \\
\hline
\end{tabular}

Table 1: Undergraduate courses with a failure rate $\geq 50 \%$

In order to establish a baseline, 19 courses with failure rates $\leq 25 \%$ were selected to represent a cross section of the three undergraduate year groups that best resembled the high fails group (see Table 2). The group with the high failure rate represents the lowest attaining group but the baseline group was selected not just to offer a sample of courses with low failure rates but also to minimise the impact of some of the variables found in the literature. Therefore the spread of class size, academic discipline and year of study are approximately the same in both groups. The research populations were also similar - there were 1734 students enrolled on the courses with high failure rates and 1735 students enrolled on the 'baseline' courses. In total 886 students 
from the baseline group completed SEQs - a response rate of 51\%, which is only slightly below the university average.

\begin{tabular}{|c|c|c|c|c|c|}
\hline $\begin{array}{c}\text { Course } \\
\text { no. }\end{array}$ & $\begin{array}{c}\text { Year of } \\
\text { study }\end{array}$ & $\begin{array}{c}\text { No. of } \\
\text { students } \\
\text { registered }\end{array}$ & Failure (\%) & $\begin{array}{c}\text { Actual No. } \\
\text { of fails }\end{array}$ & $\begin{array}{c}\text { No. of students } \\
\text { who } \\
\text { completed SEQ }\end{array}$ \\
\hline $\mathbf{2 0}$ & 3 & 44 & 0 & 0 & 24 \\
\hline $\mathbf{2 1}$ & 3 & 38 & 0 & 0 & 15 \\
\hline $\mathbf{2 2}$ & 2 & 118 & 1 & 1 & 32 \\
\hline $\mathbf{2 3}$ & 3 & 95 & 3 & 3 & 59 \\
\hline $\mathbf{2 4}$ & 3 & 19 & 5 & 1 & 11 \\
\hline $\mathbf{2 5}$ & 1 & 101 & 7 & 7 & 51 \\
\hline $\mathbf{2 6}$ & 3 & 40 & 8 & 3 & 18 \\
\hline $\mathbf{2 7}$ & 2 & 65 & 8 & 5 & 34 \\
\hline $\mathbf{2 8}$ & 2 & 82 & 9 & 7 & 38 \\
\hline $\mathbf{2 9}$ & 2 & 51 & 10 & 5 & 19 \\
\hline $\mathbf{3 0}$ & 2 & 17 & 12 & 2 & 6 \\
\hline $\mathbf{3 1}$ & 1 & 377 & 14 & 326 & 307 \\
\hline $\mathbf{3 2}$ & 1 & 114 & 15 & 17 & 30 \\
\hline $\mathbf{3 3}$ & 1 & 58 & 17 & 10 & 46 \\
\hline $\mathbf{3 4}$ & 2 & 61 & 20 & 12 & 38 \\
\hline $\mathbf{3 5}$ & 3 & 22 & 23 & 5 & 13 \\
\hline $\mathbf{3 6}$ & 2 & 164 & 24 & 39 & 79 \\
\hline $\mathbf{3 7}$ & 2 & 50 & 24 & 12 & 5 \\
\hline $\mathbf{3 8}$ & 1 & 219 & 25 & 54 & 61 \\
\hline & & & & & \\
\hline
\end{tabular}

Table 2: 'Baseline' courses with a failure rate $\leq 25 \%$

\section{Data Analysis}

\section{Establishing a baseline}

The 19 'baseline' courses were analysed using emergent content analysis to establish the areas where students felt courses could be improved. Miles and Huberman (1994) note that qualitative responses can result in an overload of data and advise that coding is a method for reducing the overload. Kerlinger (1970) defines coding as the translation of responses into categories in order to produce analysis. This analysis adopted Miles and Huberman's (1994) approach of analysing grounded theory data by means of three concurrent activities: data reduction; data display, and conclusion drawing and verification. This approach was adopted as it allowed for emergent coding that would permit the data to 'speak' and offer distinct student-generated codes (as opposed to template coding which might lead to the imposition of ideals from the researcher or from literature that might mistranslate the student voice). Data was reduced by means of highlighting frequencies of occurrences to note themes and patterns. Themes were categorised to 
make sense of the data; to provide the opportunity to explore any differences; and to establish variables. Adopting this approach allowed the student voice to emerge. Not all students completed all the sections of the questionnaire. Some students wrote very little and some wrote quite a lot. In the end 368 sections of texts were coded. The key themes are show in Table 3.

Only $51 \%$ of students who were enrolled in the selected 'baseline' courses completed the SEQ, and less than half of these students responded to the question, 'How do you think this course could be improved?' Although the suggestion that there should be 'More audio-visual resources' was coded most often, there is no real significant bias of number towards this suggestion as there is only a narrow spread of responses and the number of times this category was coded for is not particularly higher than the next four categories. Therefore, the difference between this field and the subsequent fields appears to be minor with all the responses part of a common inclination. The call for more audio-visual resources might also be seen as part of a general trend in higher education towards the use of information communication technology and might also be grouped with the suggestion that more online resources be used. The second most coded category was 'More interaction/practical work' and another 'resource' based issue was the third most coded aspect of data, with students suggesting that more library books might help their studies. This suggestion was particularly popular with Year 3 students and might be seen as a prelude to final examination.

\begin{tabular}{|l|c|c|c|c|}
\hline & Year 1 & Year 2 & Year 3 & Total \\
\hline More audio-visual resources & $\checkmark$ & $\checkmark$ & $\checkmark$ & 40 \\
\hline More interaction/practical work & $\checkmark$ & $\checkmark$ & $\checkmark$ & 37 \\
\hline More books in library & $\checkmark$ & $\checkmark$ & $\checkmark$ & 34 \\
\hline Less teaching & $\checkmark$ & $\checkmark$ & $\checkmark$ & 33 \\
\hline More subject-specific content & $\checkmark$ & $\checkmark$ & $\checkmark$ & 32 \\
\hline No change needed & $\checkmark$ & $\checkmark$ & $\checkmark$ & 30 \\
\hline More/better resources (online) & $\checkmark$ & $\checkmark$ & $\checkmark$ & 29 \\
\hline Better assessment methods and procedures & $\checkmark$ & $\checkmark$ & $\checkmark$ & 25 \\
\hline Less group work & $\checkmark$ & $\checkmark$ & $\checkmark$ & 22 \\
\hline More support for exams & & $\square$ & $\checkmark$ & 19 \\
\hline More tutorials & $\checkmark$ & $\checkmark$ & $\checkmark$ & 15 \\
\hline Consider time of class & & & $\checkmark$ & 14 \\
\hline Less content & $\checkmark$ & $\checkmark$ & & 13 \\
\hline Make objectives clearer & & $\checkmark$ & $\checkmark$ & 11 \\
\hline Better environment & $\checkmark$ & & & 8 \\
\hline Link to real world & & $\checkmark$ & & 6 \\
\hline
\end{tabular}

$\checkmark$ - this field was highlighted as significant

$\square$ - this field was highlighted as being especially important to this year group

Table 3: How students report 'baseline' courses could be improved

Of some interest is the call for less teaching yet more interaction. These two suggestions seem at odds, but there is no reason to suggest that the student body would have a coherent vision in this regard. Notwithstanding this view, it might well be that students are discerning enough to 
determine that didactic methods that are teacher-centred work less for them than more learnercentred methods. Other suggestions tend towards particular improvements and specific needs. Overall the baseline data suggests that the students in these courses have few suggestions to make regarding course improvement; that there is no evidence to suggest that the teaching needs to be improved, but that students tended to identify specific areas for improvement. This is evidenced through an overview of the 16 fields where there is a balance of responses from students showing that their focus is spread between teaching-related improvement and resourcerelated improvement - with a sizable group suggesting that no change is needed. This balance of responses would suggest that students are looking to 'tighten' rather than fundamentally overhaul courses.

\section{Courses with high failure rates}

The SEQs from the courses with high failure rates were scrutinised using the same form of emergent content analysis as that applied to the baseline courses. This led to 449 sections of texts being coded as shown in Table 4.

Only $44 \%$ of students who were enrolled in the selected courses completed the SEQ suggesting that $56 \%$ of students were not present at the end of the course. It is normal for student attendance to drop as a course progresses; however such a low attendance rate seems to suggest that many students voted with their feet and simply decided not to attend. Less than half of the students completing the questionnaire responded to the question, 'How do you think this course could be improved?' which suggests that most did not feel that a response was needed or that they declined to answer. Although fewer students in the 'high failure' group completed the SEQ, a higher proportion offered suggestions for improvement. Two categories showed significantly higher coding rates than the baseline group and these, together with the subsequent two categories, offer a picture of a student body that feels it has been poorly informed; poorly taught, and that better tutorials would offer an opportunity to resolve this. Overall the data in Table 4 shows an inclination towards improvements in the communication of course information through tutorials, better teaching, and more interaction. 


\begin{tabular}{|l|c|c|c|c|}
\hline & Year 1 & Year 2 & Year 3 & Total \\
\hline More tutorials & $\checkmark$ & $\checkmark$ & $\checkmark$ & 83 \\
\hline Clearer/better presentation of information & $\checkmark$ & $\checkmark$ & $\checkmark$ & 60 \\
\hline More interaction/practical work & $\checkmark$ & $\checkmark$ & $\checkmark$ & 39 \\
\hline Better teaching & $\checkmark$ & $\checkmark$ & $\checkmark$ & 36 \\
\hline Less content & $\checkmark$ & $\checkmark$ & $\checkmark$ & 34 \\
\hline Better assessment methods and procedures & $\checkmark$ & $\checkmark$ & $\checkmark$ & 30 \\
\hline Better structure & $\checkmark$ & $\checkmark$ & $\checkmark$ & 28 \\
\hline More/better resources (online) & $\checkmark$ & $\checkmark$ & $\checkmark$ & 28 \\
\hline More/better resources (hard copy) & $\checkmark$ & $\checkmark$ & $\checkmark$ & 25 \\
\hline More teaching & $\checkmark$ & $\checkmark$ & $\checkmark$ & 21 \\
\hline Don't assume that students understand & $\checkmark$ & $\checkmark$ & $\checkmark$ & 17 \\
\hline More support for exams & $\checkmark$ & $\checkmark$ & $\checkmark$ & 13 \\
\hline More audio-visual resources & $\checkmark$ & & $\checkmark$ & 9 \\
\hline Consider time of class & $\checkmark$ & $\checkmark$ & & 7 \\
\hline Make objectives clearer & & $\checkmark$ & $\checkmark$ & 6 \\
\hline Better support & $\checkmark$ & & $\checkmark$ & 4 \\
\hline More subject-specific content & $\checkmark$ & & & 3 \\
\hline Link to real world & & $\checkmark$ & $\checkmark$ & 3 \\
\hline Better environment & $\checkmark$ & & & 1 \\
\hline Increase entry qualifications & & & $\checkmark$ & 1 \\
\hline More focus on fundamentals & & & 1 \\
\hline
\end{tabular}

$\checkmark$ - this field was highlighted as significant

$\square$ - this field was highlighted as being especially important to this year group

Table 4: How students report courses with high failure rates could be improved

\section{Findings and implications for practice}

The low number of students completing the SEQ questionnaire is an indication that students seemed less likely to attend certain classes and it was these classes that had the higher failure rate. This either means that students did not learn as they did not attend, or that the learning in the course was not adequate - either way the courses can address this by examining what it is that turns students off of them.

Students were more likely to offer suggestions for improvement in the courses that had high failure rates (56\% of students who completed the SEQ in courses with very high failure rates had suggestions for improvement, against $21 \%$ of the baseline group). This means that students are perceptive and can clearly see where there is room for improvement. This is particularly important when we consider that a large number of students were absent when the SEQ was 
completed and, if this number contains students who had stopped attending as they were disaffected, then the actual number of suggestions for improvement could be significantly higher. It is suggested that the student voice be recognised and that the suggestions put forward for improvement are addressed at course level and made known to the relevant students. None of the suggestions made by the students are outlandish, and many other courses may already have strengths in these areas.

The following recommendations are drawn specifically from the 19 courses with high failure rates but may be generalisable to other courses where course co-ordinators seek to increase student success rates. It is hoped that courses with high failure rates address these issues as a matter of priority but other courses use them as part of their continuous course improvement strategy:

1. Course co-ordinators/lecturers should consider what it is about tutorials that make them a preferred learning experience.

Learning at university is often split in three: lecture, tutorial and independent study. Of these, the tutorial offers most scope for interaction through student inquiry. Tutorials offer students a chance to access the underpinning knowledge that is essential to a course. In calling for more tutorials, students are not calling for 'more of the same' and it cannot be expected that their mere presence in a tutorial resolves any perceived issues since 'physical presence and intellectual involvement are quite different phenomenon' (Rodgers, 2002, p.265); therefore practitioners might do well to examine current tutorial practice and work out just what it is that students want more of. Here it is suggested that students want good teaching.

2. Lecturers consider how they interact with, engage, and support their students.

The university has moved beyond the simple either/or perspectives on teaching and research. University education involves a blend of teaching methods supported by relevant research and job roles are designed to support this. This perspective is outlined in HR contracts and often in universities' mission statements where the role of teaching is clearly given significance. If student learning outcomes are to be achieved, then academic staff need to embrace a student-centred perspective. Here it is suggested that universities place greater emphasis on the quality of teaching such that all staff know its value in relation to the learning experience. It is recommended that an audit of all academic staff be undertaken in order to find out their training needs in relation to becoming student-centred facilitators of learning.

3. Lecturers consider the value of interaction and reflect if there is scope to increase the number of interactive learning tasks in a course.

Students in both groups examined felt that there was a need for more interaction and practical work. Whilst it is fair to say that some aspects of university learning are not easily converted into practical activity, it is not beyond the scope of any member of the teaching staff to increase the number of interactions within their course. These can be both lecturer-student and student-student but may also include intra-student reflection on questions/scenarios. There is clear evidence to show that verbal exposition is a poor tool for higher order learning and that knowledge constructed through interaction is easier to remember and more applicable to new circumstances. The tutorial is an ideal arena for interaction and this may be one of the reasons why students seemed to value it, but interaction can also be instigated in 
the lecture theatre and followed up through online discussion boards, blogs and wikis. It is recommended that all academic staff identify where interactive activities can be introduced into their course and do so forthwith.

4. The way information is presented should be examined by course co-ordinators/lecturers many students spoke about crammed PowerPoint presentations.

The use of PowerPoint has become ubiquitous in teaching, yet few lecturers have been 'trained' in its use. The software itself is hugely malleable and has great potential to support teaching yet it seems underused or poorly used. PowerPoint is a visual media that has come from the business world, where it was initially used to show graphs, forecasts and such. In its move to education there seems to be a reduction in the way that it has been used and slides are now found to be crammed with written text that too many lecturers simply read to students. A Google search for the phrase 'Death by PowerPoint' found 3,690,000 results and another for the phrase 'I hate PowerPoint' found 4,160,000 results. Using PowerPoint to display large quantities of text is reductive in two ways - it reduces the value of this tool to display supportive illustrations and it reduces the role of the lecturer to mere narrator. The power of the lecture is lost if the lecturer becomes subservient to large blocks of written text. It is recommended that lecturers review the way in which they use PowerPoint and attend training sessions on PowerPoint usage as a way to enhance their presentations.

\section{Materials are posted online regularly through virtual learning environments}

In a world of mobile devices and hyperconnectivity, a university that ignores the role of technology fails to acknowledge the lived experiences of its students. Whilst it is recognised that any virtual learning environment (VLE) may seem stuffy in comparison to social media, there is clearly much merit in having a range of online resources available for students. Most universities use VLEs and some are used well; however if lecturers fail to upload materials then they ignore the potential of this tool. Many universities have positioned themselves such that there is now a clear focus on the role and value of blended learning; therefore, as each university moves towards a more blended mode of delivery, the role of the VLE becomes more and more significant. It is recommended that universities conduct an audit of their VLE usage and update policies on usage so as to establish a minimum requirement for each course. Training needs should also be identified and good practice shared.

\section{Final Remark}

The student voice offers a valuable insight into the learning experience and, as such, has agency and power. In developing higher education practice, no tool should be overlooked. Whilst this research was undertaken in a particular context and local/cultural factors may be at play, the number of participants involved suggests that the research itself is more than a small scale case study and that there may be implications here for other universities. From this perspective, two suggestions are made regarding what this might mean for wider higher education practice. The first suggestion might be seen as a 'quick fix' but it is hoped that the second will lead to a more rigorous enhancement of practice. Firstly, where universities have identified undergraduate courses with high failure rates they may wish to consider adopting some (or all) of the five recommendations. Secondly, universities should seek to find context-specific solutions by adopting the above methods so that they can listen to the voice of their students (and act upon it). 


\section{References}

Bedard, K. and Kuhn, P. (2008) 'Where class size really matters: Class size and student ratings of instructor effectiveness'. Economics of Education Review. 27 (3): 253-265. http://dx.doi.org/10.1016/j.econedurev.2006.08.007

Beran, T. (2005) 'Ratings of university teacher instruction: how much do student and course characteristics really matter?'. Assessment \& Evaluation in Higher Education. 30 (6): 593-601. http://dx.doi.org/10.1080/02602930500260688

Bornholt, L., and Möller, J. (2003) 'Attributions about achievement and intentions about further study in social context'. Social Psychology of Education. 6 (3): 217-231. http://dx.doi.org/10.1023/A:1024715609124

Chamorro-Premuzic, T. \& Furnham, A. (2005). Personality and intellectual competence. Mahwah, NJ: Lawrence Erlbaum.

Chanock, K. (2007) 'What academic language and learning advisors bring to the scholarship of teaching and learning: Problems and possibilities for dialogue with the disciplines'. Higher Education Research \& Development. 26 (3): 269-280. http://dx.doi.org/10.1080/07294360701494294

Clayson, D. E. (2009) 'Student evaluations of teaching: Are they related to what students learn? A meta-analysis and review of the literature'. Journal of Marketing Education. 31 (1): 16-30. http://dx.doi.org/10.1177/0273475308324086

Clayson, D. E., and Haley, D. A. (2011) 'Are Students Telling Us the Truth? A Critical Look at the Student Evaluation of Teaching'. Marketing Education Review. 21 (2): 101-112. http://dx.doi.org/10.2753/MER1052-8008210201

Cook-Sather, A. (2006) 'Sound, Presence, and Power: Exploring "Student Voice" in Educational Research and Reform'. Curriculum Inquiry. 36 (4): 359-390. http://dx.doi.org/10.1111/j.1467-873X.2006.00363.x

Emery, C. R., Kramer, T. R., and Tian, R. G. (2003) 'Return to academic standards: a critique of student evaluations of teaching effectiveness'. Quality Assurance in Education. 11 (1): 37-46. http://dx.doi.org/10.1108/09684880310462074

Forsyth, D., Story, P., Kelley, K., and McMillan, J. (2009) 'What causes failure and success? Students' perceptions of their academic outcomes'. Social Psychology of Education. 12 (2): 157174. http://dx.doi.org/10.1007/s11218-008-9078-7

Foster, G. (2010) 'Teacher effects on student attrition and performance in mass-market tertiary education'. Higher Education. 60 (3): 301-319. http://dx.doi.org/10.1007/s10734-009-9301-2 
Freeman, H. R. (1994) 'Student evaluations of college instructors: Effects of type of course taught, instructor gender and gender role, and student gender'. Journal of Educational Psychology. 86 (4): 627-630. http://dx.doi.org/10.1037/0022-0663.86.4.627

Giorgi, A. (1994). 'A phenomenological perspective on certain qualitative research methods'. Journal of Phenomenological Psychology. 25 (2): 190-220.

http://dx.doi.org/10.1163/156916294X00034

Good, T. and Brophy, J. (2003) Looking in Classrooms. Ninth Edition. New York: Macmillan.

Greenwald, A. G. (2002) Constructs in Student Ratings of Instructors. In Braun, H. I., Jackson, D. N. and Wiley, D. E. (eds) The Role of Constructs in Psychological and Educational Measurement. New York: Erlbaum.

Haynes Stewart, T. L, Clifton, R. A., Daniels, L. M., Perry, R. P., Chipperfield, J. G. and Ruthig, J. C. (2011) 'Attributional retraining: reducing the likelihood of failure'. Journal of Social and Clinical Psychology. 14 (1): 75-92.

Hellman, C. M. (1998) 'Faculty evaluation by students: a comparison between full-time and adjunct faculty'. Journal of Applied Research in the Community College. 6 (1): 45-50.

Kember, D. (1997) 'A reconceptualization of the research into university academics' conceptions of teaching'. Learning Instruction. 7 (3): 255-275.

http://dx.doi.org/10.1016/S0959-4752(96)00028-X

Kember, D. (2000) 'Misconceptions about the learning approaches: Motivation and study practices of Asian students'. Higher Education. 40 (1): 99-121.

http://dx.doi.org/10.1023/A:1004036826490

Kerlinger, F. N. (1970) Foundations of Behavioural Research. New York: Holt, Rinehart and Winston.

Kotze, T. G. and Du Plessis, P. J. (2003) 'Students as co producers of education: A proposed model of students' socialization and participation at tertiary institutions'. Quality Assurance in Education. 27 (1): 27-52.

Layne, B. H., DeCristoforo, J. R. and McGinty, D. (1999). 'Electronic Versus Traditional Student Ratings of Instruction'. Research in Higher Education. 40 (2): 221-232. http://dx.doi.org/10.1023/A:1018738731032

Ling, J., Heffernan, T. M. and Muncer, S. J. (2003) 'Higher education students' beliefs about the causes of examination failure: A network approach'. Social Psychology of Education. 6 (2): 159170. http://dx.doi.org/10.1023/A:1023289908438 
Ling, F. Y. Y, Ng, P. K. and Leung, M-Y. (2011) 'Predicting the academic performance of construction engineering students by teaching and learning approaches: case study'. Journal of Professional Issues in Engineering Education \& Practice. 137 (4): 277-284. http://dx.doi.org/10.1061/(ASCE)EI.1943-5541.0000060

Lizzio, A., Wilson, K. and Simons, R. (2002) 'University students' perceptions of the learning environment and academic outcomes: implications for theory and practice'. Studies in Higher Education. 27 (1): 27-52. http://dx.doi.org/10.1080/03075070120099359

Magnusson, J. L. (1998) The Evaluation of University Teaching: Exploring the Question of Resistance. Ontario Institute of Education: University of Toronto.

Margaret, B. and Guest, R. (2007) 'A conversation about pedagogical responses to increase diversity in university classrooms'. Higher Education Research \& Development. 26 (2): 133-146. http://dx.doi.org/10.1080/07294360701310771

Marsh, H. W. (1984) 'Students' evaluations of university teaching: Dimensionality, reliability, validity, potential biases, and utility'. Journal of Educational Psychology. 76 (5): 707-754. http://dx.doi.org/10.1037/0022-0663.76.5.707

Marsh, H.W. (1987) 'Students evaluations of university teaching: Research findings, methodological issues, and directions for future research'. International Journal of Educational Research. 11 (3): 253-388. http://dx.doi.org/10.1016/0883-0355(87)90001-2

Marsh, H. W. and Bailey, M. (1993) 'Multidimensional students' evaluations of teaching effectiveness: a profile analysis'. Journal of Higher Education. 64 (1): 1-18. http://dx.doi.org/10.2307/2959975

McKeachie, W. J., Pintrich, P. R, Yi-Guang, L. and Smith, D. A. F. (1986) Teaching and Learning in the College Classroom: A Review of the Research Literature. MI: The University of Michigan.

McPherson, M., Jewell, R. and Kim, M. (2009) 'What Determines Student Evaluation Scores? A Random Effects Analysis of Undergraduate Economics Classes'. Eastern Economic Journal. 35 (1): 37-51. http://dx.doi.org/10.1057/palgrave.eej.9050042

Miles, M. B. and Huberman, M. (1994) Qualitative Data Analysis: An Expanded Sourcebook. Thousand Oaks, CA: Sage.

Mortenson, S. (2006) 'Cultural Differences and Similarities in Seeking Social Support as a Response to Academic Failure: A Comparison of American and Chinese College Students'. Communication Education. 55 (2): 127-146. http://dx.doi.org/10.1080/03634520600565811

Patrick, C. L. (2011) 'Student evaluations of teaching: effects of the Big Five personality traits, grades and the validity hypothesis'. Assessment \& Evaluation in Higher Education. 36 (2): 239249. http://dx.doi.org/10.1080/02602930903308258 
Peelo, M. (2002) Setting the Scene. In Peelo, M. and Wareham, T. (eds) Failing Students in Higher Education. Buckingham: Open University Press.

Piccinin, S., Cristi, C. and McCoy, M. (1999) 'The impact of individual consultation on student ratings of teaching'. International Journal for Academic Development. 4 (2): 75-88. http://dx.doi.org/10.1080/1360144990040202

Reneland, L. and Ahlbäck, T. (2003) Quality interaction, collaboration and web-based learning: A study of a teacher training. Proceedings of the annual HERDSA conference, July 3-6, 2003, Christchurch, New Zealand.

Richardson, J., Slater, J. and Wilson, J. (2007) 'The national student survey: Development, findings and implications'. Studies in Higher Education. 32 (5): 557-580.

http://dx.doi.org/10.1080/03075070701573757

Rodgers, J. R. (2002) 'Encouraging tutorial attendance at university did not improve performance'. Australian Economic Papers. 41 (3): 255-266.

http://dx.doi.org/10.1111/1467-8454.00163

Seale, J. (2009) 'Doing student voice work in higher education: an exploration of the value of participatory methods'. British Educational Research Journal. 36 (6): 995-1015. http://dx.doi.org/10.1080/01411920903342038

Spencer, K. J and Schmelkin, L. P. (2002) 'Student perspectives on teaching and its evaluation'. Assessment \& Evaluation in Higher Education. 27 (50): 397-409. http://dx.doi.org/10.1080/0260293022000009285

Struthers, C. W., Menec, V. H., Schonwetter, D. J. and Perry, R. P. (1996) 'The effects of perceived attributions, action control, and creativity on college students' motivation and performance: A field study'. Learning and Individual Differences. 8 (2): 121-139. http://dx.doi.org/10.1016/S1041-6080(96)90029-1

Thielens, W. Jr. (1987) The disciplines and undergraduate lecturing. Paper presented at the annual meeting of the American Educational Research Association, 20-24th April. Washington, DC.

Tucker, B., Jones, S. and Staker, L. (2008) 'Online student evaluation improves course experience questionnaire: results in a physiotherapy program'. Higher Education Research and Development. 27 (3): 281-96. http://dx.doi.org/10.1080/07294360802259067

Turner, J., Husman, J. and Schallert, D. (2002). 'The Importance of Students' Goals in Their Emotional Experience of Academic Failure: Investigating the Precursors and Consequences of Shame'. Educational Psychologist. 37 (2): 79-89. http://dx.doi.org/10.1207/S15326985EP3702_3 
Weiner, B. (1995) Judgements of Responsibility: A Foundation for a Theory of Social Conduct. Guildford Press: New York, NY.

Weinberg, B. A., Hashimoto, M. and Fleisher, B. M. (2009) 'Evaluating Teaching in Higher Education'. Journal of Economic Education. 40 (3): 227-261.

http://dx.doi.org/10.3200/JECE.40.3.227-261

Wimshurst, K. and Allard, T. (2008) 'Personal and institutional characteristics of student failure'. Assessment \& Evaluation in Higher Education. 33 (6): 687-698.

http://dx.doi.org/10.1080/02602930701772911

Wongsurawat, W. (2011) 'What's a comment worth? How to better understand student evaluations of teaching'. Quality Assurance in Education. 19 (1): 67-83.

http://dx.doi.org/10.1108/09684881111107762

\section{About the author}

Erik Blair is a Research Fellow of the Centre for Excellence in Teaching and Learning at The University of the West Indies, St. Augustine, Trinidad and Tobago, West Indies.

Email: erik.blair@sta.uwi.edu 